RESEARCH NOTE

\title{
New detections extend the known range of the state-threatened Sierra Nevada red fox
}

\author{
BRIAN E. HATFIELD ${ }^{1 *}$, JULIA M. RUNCIE ${ }^{1}$, ELIZABETH A. SI- \\ EMION $^{1}$, CATE B. QUINN ${ }^{2}$, AND THOMAS R. STEPHENSON ${ }^{1}$ \\ ${ }^{1}$ California Department of Fish and Wildlife, Inland Deserts Region 6, Bishop Field Office, \\ 787 N Main St Suite 220, Bishop, CA, USA \\ ${ }^{2}$ Mammalian Ecology and Conservation Unit, Veterinary Genetics Laboratory, University \\ of California, Davis, Davis, CA 95616, USA \\ *Corresponding Author: brian.hatfield@wildlife.ca.gov
}

Key words: alpine, carnivore, California Endangered Species Act, noninvasive, remote cameras, Sierra Nevada, Sierra Nevada red fox, state-threatened, Vulpes vulpes necator

The Sierra Nevada red fox (Vulpes vulpes necator; SNRF) is a subspecies of red fox native to the upper montane, subalpine, and alpine zones of the Sierra Nevada and Cascades in California and Oregon (Grinnell et al. 1937; Perrine et al. 2010; Sacks et al. 2010). Declines in the distribution and abundance of SNRF populations led to the designation of the subspecies as state-threatened in California in 1980 (Gould 1980). More recently, the remnant population in the Sierra Nevada was proposed for federal listing as an endangered Distinct Population Segment (USFWS 2020). Lack of certainty as to the distribution of remnant SNRF populations has hindered conservation efforts and population recovery. Using noninvasive survey techniques, we documented the southernmost SNRF detections in recent decades, greatly expanding the known contemporary range of this state-threatened subspecies (Perrine et al. 2010; Hatfield et al. 2020).

Although the subspecies existed historically as far south as the Mt. Whitney region (Grinnell et al. 1937), the verified contemporary distribution of SNRF in the Sierra Nevada is far more restricted. Prior to 2010, the last confirmed detection in the Sierra Nevada was a photograph taken in 1991 on the Inyo National Forest near Tioga Pass in Yosemite National Park (Perrine et al. 2010). Although there were several observations of apparent red foxes in the southern Sierra Nevada during the 1960s-1990s (Schempf and White 1977; Perrine et al. 2010), the last confirmed SNRF detections south of Yosemite National Park were reported by Grinnell et al. (1937). In 2010, a U.S. Forest Service survey documented SNRF near Sonora Pass, north of Yosemite National Park (Statham et al. 2012). Between 2010-2013, confirmed detections of red foxes in the Sierra Nevada were limited to an approximately $30-\mathrm{km}$ stretch of the Sierra Crest immediately north of Yosemite National Park (Quinn et al. 2019).

The scarcity of contemporary SNRF detections may indicate local extirpations, but may also be due to insufficient survey effort. Because SNRF exist at very low densities in 
remote, high-elevation areas, documenting their distribution can be extremely challenging. Most previous systematic surveys targeted multiple species and were optimized for mustelids (e.g., Zielinski et al. 2005; Green 2006; IWS 2006; Perrine et al. 2010), which have different habitat requirements and behaviors than SNRF. Only a small number of previous surveys were conducted in the high-elevation habitat historically ascribed to SNRF, using methods with high probabilities of detection for canids (Statham et al. 2012; Stock and Eyes 2017; Quinn et al. 2019; CDFW, unpublished data).

In 2013, a noninvasive genetic study documented apparent SNRF population growth in the Sonora Pass area, immediately following immigration from a nearby population (Quinn et al. 2019). The observed increase in reproductive output and local abundance raised the possibility that SNRF could be expanding their distribution and suggested a need for systematic surveys throughout the historical range. In 2014, SNRF were documented in northern Yosemite National Park (Stock and Eyes 2017). In 2015, we began implementing noninvasive SNRF surveys at elevations above 2,700 $\mathrm{m}$ between the southern boundary of Yosemite National Park and the northern boundary of Kings Canyon National Park (Fig. 1). We used a combination of baited camera stations during the winter and scat surveys during the summer and fall to survey for SNRF.

Each fall, we selected a focal watershed containing potential SNRF habitat (Cleve et al. 2011). We applied a sampling frame of 10.4- $\mathrm{km}^{2}$ hexagonal cells across the selected watershed, placing two remote cameras (Reconyx, Holmen, Wisconsin, USA; Stermer et al. 2015) per sampling cell with at least $1.6 \mathrm{~km}$ between cameras (e.g., Stermer et al. 2015). We attached cameras to trees or large boulders using bungee cord or parachute cord. We baited each station with a scent lure $5 \mathrm{~m}$ away from the camera to attract carnivores (Gusto, Minnesota Trapline Products, Pennock, MN, USA). Each annual survey consisted of 10 to 15 sampling cells containing 20-30 cameras, operational during October-June at minimum. Between 2015-2020, we deployed 114 survey cameras (average 18.4 per annual survey) which were operational for 23,262 total days (average 4,652.4 operational days per annual survey; Table 1). Because cameras would need to remain operational through winter, we prioritized camera placement on high-elevation passes and ridges that were exposed to prevailing winds and unlikely to become buried in snow. We suspected that these windswept, geographically constrained features might also function as travel corridors for wildlife. In addition to cameras deployed within a systematic survey framework, we maintained passive monitoring cameras year-round in locations where we detected SNRF or where camera placements were easily accessible to surveyors. We used similar methods to deploy passive monitoring and survey cameras, but passive cameras were not deployed according to a systematic framework.

We followed camera surveys with scat surveys during the summer and fall to collect fecal material for genetic analysis. Surveyors traversed ridges, passes, and trails in sampling cells where cameras had detected SNRF and collected all apparent mesocarnivore scats. The Mammalian Ecology and Conservation Unit at the University of California, Davis conducted genetic analysis of scat samples, using mitochondrial sequences to confirm species, and nuclear microsatellites and a sex marker to identify individuals (e.g., Quinn et al. 2019).

Between 2015-2020, we surveyed 58 sampling cells and detected SNRF in 10 cells (Fig. 1). We did not detect SNRF in the cells surveyed between 2015-2017 (North Fork of Bishop Creek, Rock Creek, Mammoth Lakes Basin, and Humphreys Basin), indicating either that SNRF were not present in the areas we surveyed during those years or simply that our 


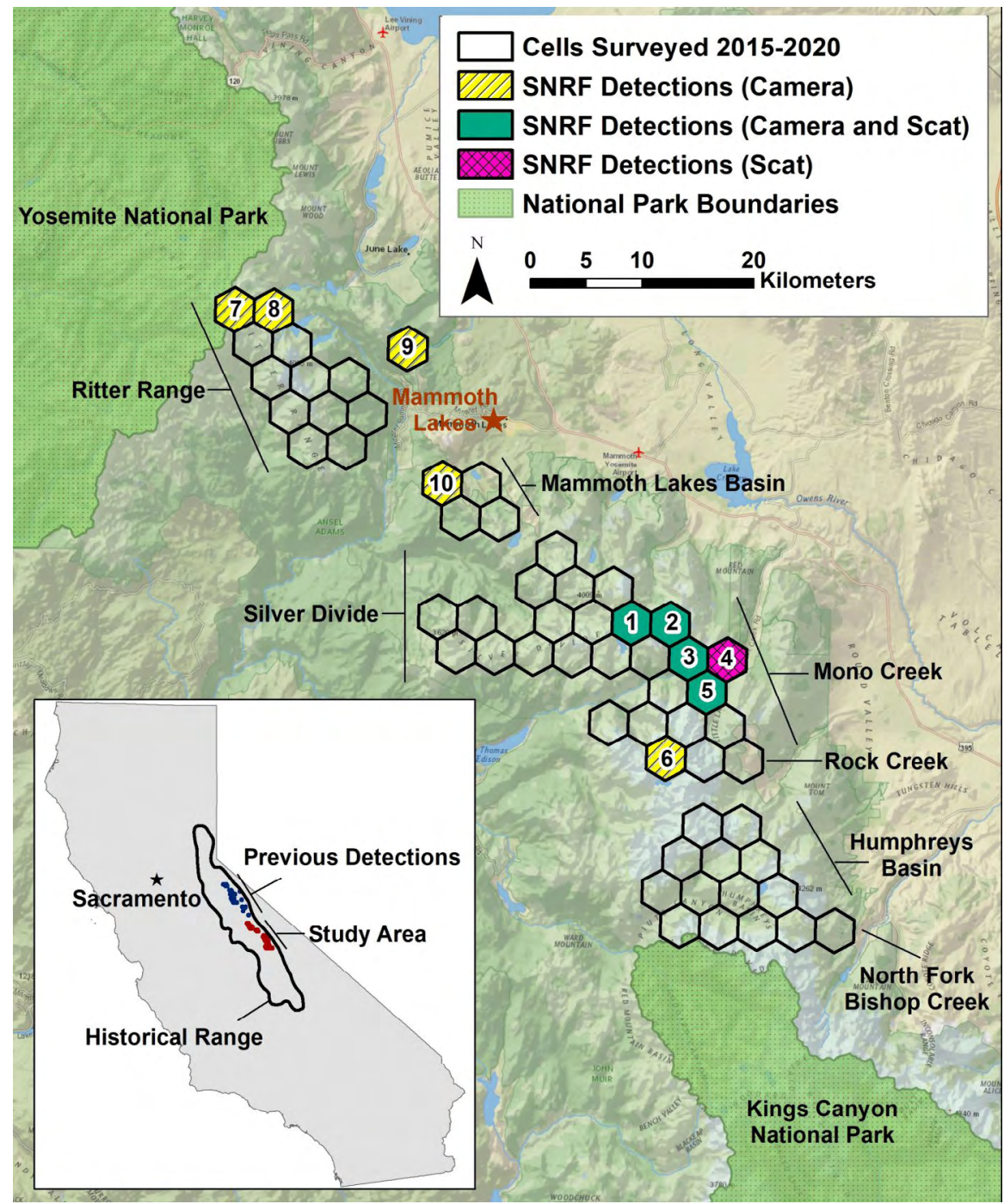

Figure 1. Locations of $10.4 \mathrm{~km}^{2}$ sampling cells where high-elevation Sierra Nevada red fox (SNRF) remote camera surveys and scat detections occurred between 2015-2020. In inset map, "Previous Detections" are from Statham et al. 2012, Stock and Eyes 2017, Quinn et al. 2019, CDFW unpublished data, National Park Service unpublished data, and U.S. Forest Service unpublished data. "Historical Range" is from Grinnell et al. 1937.

surveys failed to detect SNRF. In 2018, we detected SNRF at six camera sites within the Mono Creek watershed, southeast of the town of Mammoth Lakes (Fig. 1, cells 1, 2, 3, 5, and 6). We collected five SNRF scats within this survey area (Fig. 1, cells 1-5), representing two females and one male. The male had been detected by scat at Sonora Pass in 2017 (Quinn et al. 2019), demonstrating a dispersal of more than $120 \mathrm{~km}$ within eight months (Fig. 2). We maintained passive monitoring cameras at or near locations where survey cameras had detected SNRF, and continued to detect SNRF in the Mono Creek watershed in 2019 and 2020. During the summer and fall of 2019, we collected five SNRF scats from the Mono 
Table 1. Number of survey cameras, operational days, and Sierra Nevada red fox (SNRF) detections per study area and year for SNRF surveys between 2015-2020.

\begin{tabular}{lcccc}
\hline Study area & Year & Cameras & Operational Days & SNRF Detections \\
\hline East Side $^{\mathrm{a}}$ & 2016 & 19 & 2834 & 0 \\
Humphreys Basin & 2017 & 24 & 4475 & 0 \\
Mono Creek & 2018 & 19 & 4546 & 13 \\
Ritter Range & 2019 & 26 & 5935 & 3 \\
Silver Divide & 2020 & 26 & 5472 & 0 \\
\hline
\end{tabular}

${ }^{a}$ The East Side study area encompassed the Mammoth Lakes Basin, Rock Creek, and the North Fork of Bishop Creek.

Creek watershed and one from an adjacent watershed (McGee Creek). Genetic analysis of the scats collected in 2019 documented the same male but only one of the two females that were first detected in 2018. No new individuals were identified.

In addition to the SNRF individuals detected in the Mono Creek watershed, we also detected SNRF in 2019 and 2020 on four remote cameras located north of the Mono Creek watershed and south of Yosemite National Park. Two of the detections were in the Ritter Range, a sub-range of the Sierra Nevada west of the town of Mammoth Lakes (Fig. 1, cells 7-8). The other two detections were on the Sierra Crest in the vicinity of Mammoth Lakes (Fig. 1, cells 9-10). Although we maintained passive monitoring cameras in these locations and conducted scat surveys nearby, we have not yet obtained genetic samples or had repeat photographic detections from these sites. Therefore, we cannot confirm the number of individuals detected or whether the detections represent dispersers or resident SNRF. A camera survey conducted in 2020 in the Silver Divide, adjacent to the Mono Creek watershed, did not detect SNRF. During the winter of 2020-2021, in collaboration with the National Park Service (NPS), we will be deploying a camera survey in the northern portion of Kings Canyon National Park, approximately $15 \mathrm{~km}$ south of our southernmost detection in the Mono Creek watershed.

Our findings suggest that SNRF are more broadly distributed in the Sierra Nevada than previously suspected, although they likely exist at low density within our study area. Recent detections of SNRF in the Sierra Nevada are relatively continuous along the Sierra Crest between Ebbetts Pass and Mono Pass, with no gaps in distribution $>20 \mathrm{~km}$ (Quinn et al. 2019; Hatfield et al. 2020; CDFW, unpublished data, NPS, unpublished data). The movement of at least one individual from Sonora Pass to Mono Creek indicates some level of connectivity within the range. SNRF use the highest available elevations year-round, with detections ranging from $3,044 \mathrm{~m}$ to $3,738 \mathrm{~m}$. Continuing surveys are crucial to determine the current distribution of SNRF in the Sierra Nevada and to inform conservation and recovery efforts for this state-threatened subspecies.

\section{ACKNOWLEDGMENTS}

We are grateful to numerous CDFW personnel for fieldwork assistance, data processing, and advice, including K. Anderson, E. Brandell, T. Calfee, J. Dittli, J. Fusaro, L. Greene, J. Leary, A. Klinefelter, C. Massing, E. Otto, C. Stermer, A. Sturgill, and J. Weissman. B. Sacks of the Mammalian Ecology and Conservation Unit at the University of California, Davis supported genetic analysis of scat samples. The Inyo National Forest, Sierra National 


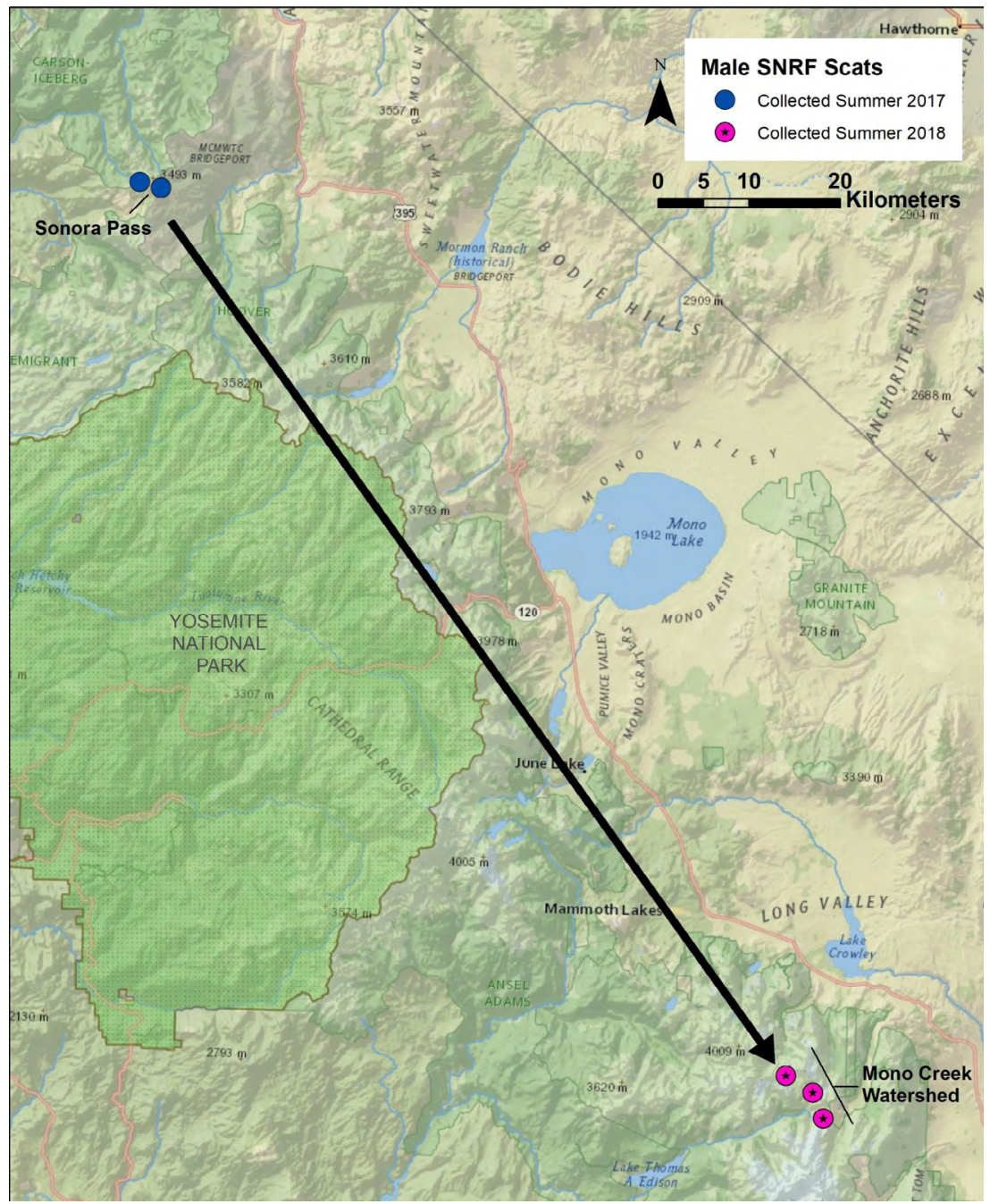

Figure 2. Locations of scat detections of a single Sierra Nevada red fox (SNRF) male in summer 2017 near Sonora Pass and in summer 2018 in the Mono Creek watershed, demonstrating a dispersal of more than $120 \mathrm{~km}$ within eight months.

Forest, and Southern California Edison assisted with backcountry survey logistics. This project was funded by the Pittman-Robertson Act (Federal Aid in Wildlife Assistance).

\section{LITERATURE CITED}

Cleve, C., J. D. Perrine, B. Holzman, and E. Hines. 2011. Addressing biased occurrence data in predicting potential Sierra Nevada red fox habitat for survey prioritization. Endangered Species Research 14:179-191.

Gould, G. I. 1980. Status of the red fox in California. California Department of Fish and Game, Nongame Wildlife Investigations, Job I-8, Sacramento, CA, USA. 
Green, R. 2006. Distribution and habitat associations of forest carnivores and an evaluation of the California Wildlife Habitat Relationships model for American marten in Sequoia and Kings Canyon National Parks. Thesis, Humboldt State University, Arcata, CA, USA.

Grinnell, J., J. Dixon, and L. Linsdale. 1937. Fur-bearing mammals of California. University of California Press, Berkeley, CA, USA.

Hatfield, B. E., E. A. Siemion, J. M. Runcie, and T. R. Stephenson. 2020. New detections of the Sierra Nevada red fox: 2015-2018 alpine mesocarnivore study progress report. California Department of Fish and Wildlife, Inland Deserts Region 6, Bishop Field Office, Bishop CA, USA.

Institute for Wildlife Studies (IWS). 2006. 2006 winter wolverine survey in Sequoia and Kings Canyon National Parks. Unpublished report. Available from: http://www. iws.org (September 2020).

Perrine, J. D., L. A. Campbell, and G. A. Green. 2010. Sierra Nevada red fox (Vulpes vulpes necator): a conservation assessment. U.S. Department of Agriculture, Washington, D.C.,USA.

Quinn, C. B., P. B. Alden, and B. N. Sacks. 2019. Noninvasive sampling reveals short-term genetic rescue in an insular red fox population. Journal of Heredity 110:559-576.

Sacks, B. N., M. J. Statham, J. D. Perrine, S. M. Wisely, and K. B. Aubry. 2010. North American montane red foxes: expansion, fragmentation, and the origin of the Sacramento Valley red fox. Conservation Genetics 11:1523-1539.

Schempf, P. F., and M. White. 1977. Status of six furbearer populations in the mountains of northern California. Department of Forestry and Conservation and Museum of Vertebrate Zoology, University of California, Berkeley, USA. U.S. Department of Agriculture, Forest Service, California Region.

Statham, M. J., A. C. Rich, S. K. Lisius, and B. N. Sacks. 2012. Discovery of a remnant population of Sierra Nevada red fox (Vulpes vulpes necator). Northwest Science $86: 122-132$.

Stermer, C. 2015. Survey protocol for the Sierra Nevada red fox for California (Draft). California Department of Fish and Wildlife, Sacramento, CA, USA.

Stock, S., and S. Eyes. 2017. Sierra Nevada red fox: competitors and prey. Final grant status report to the Yosemite Conservancy. National Park Service, Yosemite, CA, USA.

U. S. Fish and Wildlife Service (USFWS). 2020. Endangered and threatened wildlife and plants; endangered status for the Sierra Nevada Distinct Population Segment of the Sierra Nevada red fox; proposed rule. USFWS, Washington, D.C., USA.

Zielinski, W. J., R. L. Truex, F. V. Schlexer, L. A. Campbell, C. Carroll. 2005. Historical and contemporary distributions of carnivores in forests of the Sierra Nevada, California, USA. Journal of Biogeography 32:1385-1407.

Submitted 25 September 2020

Accepted 2 November 2020

Associate Editor was D. Applebee 